\title{
A POLÍTICA PRESENTE NA REFORMA DO ENSINO MÉdIO NO ESTADO dO PARANÁ: ALGUMAS REFLEXÕES SOBRE O PROEM
}

Ana Lorena Bruel ${ }^{1}$

RESUMO: Este artigo busca apresentar algumas reflexões acerca da direção política e pedagógica da reforma do ensino médio no Estado do Paraná implantada pelo Programa Expansão, Melhoria e Inovação no Ensino Médio do Paraná - PROEM, no período de 1998 a 2002, em convênio de cooperação técnica com o Banco Interamericano de Desenvolvimento - BID. A reflexão a respeito da Reforma será analisada sob três enfoques: o conteúdo dos documentos oficiais que estabeleceram o programa, o impacto de sua implementação sobre as matrículas no Ensino Médio e sobre o seu financiamento, tomando como referência os dados do período anterior e posterior à implantação das medidas relacionadas à reforma do Ensino Médio no Estado.

Palavras-chave: Ensino Médio, Reforma Educacional, matrículas no Ensino Médio regular.

ABSTRACT: This paper presents some reflections about the political e pedagogical direction of the Paraná's high school reform, implanted by the Program "Expansão, Melhoria e Inovação no Ensino Médio do Paraná - PROEM" (Expansion, Improvement and Innovation of Paraná's high school PROEM), between 1998 and 2002, in a technical cooperation convention with the Inter-American Development Bank - IDB. The reflection concerning the Reform will be analyzed in three focuses: the contents of the official documents that established the program; the impact of its implementation on the high school's registrations, and its financing, having as reference data related to the periods before and after the beginning of the Reform.

Key-words: High School; Educational Reform; High School registrations.

Considerando as condições em que se encontrava o ensino médio no período que antecedeu a implantação do PROEM - Programa Expansão, Melhoria e Inovação no Ensino Médio do Paraná, é possível perceber que o crescimento das matrículas na rede estadual de ensino do estado do Paraná permaneceu constante nas décadas de 80 e 90. Em 1999 as escolas públicas estaduais chegaram a manter $456.290^{2}$ alunos matriculados nesta etapa da educação básica em todo o estado.

Os dados de expansão da matrícula entre os anos de 1985 e 1995, fornecidos pela FUNDEPAR (Fundação - Instituto de Desenvolvimento Educacional do Paraná), demonstram que houve um crescimento de $122 \%$ no número de alunos matriculados no ensino médio em escolas públicas estaduais neste intervalo de tempo. Contudo, a expansão do ensino, assim como no âmbito federal, realizou-se de forma desorganizada, sem planejamento e sem o correspondente investimento em infra-estrutura. Em 1996, para embasar o programa que deu origem à reforma do ensino médio, a Secretaria de Estado da Educação (SEED) explicava a situação que levou à expansão quantitativa desordenada deste nível de ensino.

\footnotetext{
${ }^{1}$ Mestre em Educação pela UFPR. Professora da UNICENP. analorena @ unicenp.br.

${ }^{2}$ Dados fornecidos pelo INEP.
} 
O crescimento da oferta de Ensino Médio na rede estadual respondeu a movimentos e pressões desordenados. Lideranças políticas locais pressionaram a administração estadual para expandi-la rapidamente em diferentes pontos do estado. A exigência de educação fundamental para o ingresso no mercado de trabalho, mesmo em tarefas de baixa qualificação, gerou crescente procura do ensino supletivo para conclusão da escolaridade obrigatória. Os egressos do supletivo tornaram-se demandatários potenciais de Ensino Médio, somados ao aumento dos concluintes de $8^{\text {a }}$ série do ensino Fundamental regular (PROEM, 1996, p. 8).

A explicação oficial, embora faça referência a questões centrais para a compreensão da situação do ensino médio no estado, não analisa que a falta de uma política pública responsável e adequada foi o entrave fundamental para a expansão qualitativa do ensino. Não se pode subestimar a importância de fatores externos, como as exigências do mercado de trabalho, mas a pressão intra-sistêmica provocada pelo aumento do número de alunos que passaram a concluir o ensino fundamental regular e supletivo poderia ter sido prevista e planejada.

Outra característica marcante do ensino médio no estado no final deste período que antecede a reforma é a concentração das matrículas nos cursos de formação profissional. De acordo com as informações da SEED, em 1995, dos 351.738 alunos matriculados no ensino médio regular - diurno e noturno - no estado do Paraná, 205.841 alunos, quase 60\%, freqüentava cursos de formação profissional voltados à habilitação para diversos setores da economia. Destes 205.841 alunos, $90 \%$ estavam matriculados em cursos dirigidos para o setor terciário, sendo que grande parte das matrículas concentrava-se nos cursos de magistério e contabilidade.

Estes dados demonstram que um ano antes do início do processo de divulgação e implementação da reforma do ensino médio no estado no Paraná, que teve como uma de suas principais conseqüências o fechamento dos cursos profissionalizantes mantidos pelo poder público estadual, a grande maioria dos alunos buscava a formação profissional, sobretudo ligada ao setor terciário da economia.

A opção dos jovens alunos do ensino médio por cursos de formação profissional manifesta a inquietação com a terminalidade dos estudos e a necessidade de inserção no mercado do trabalho, sobretudo em tempos de desemprego estrutural, que já se materializava como um dos grandes problemas sociais na década de 90. Porém, a escolha destes jovens, que muitas vezes não fizeram uma opção de fato, mas foram levados à profissionalização pelas condições concretas de vida, não pode ser utilizada como único critério para a defesa de continuidade da profissionalização. 
A partir de 1996, as escolas foram levadas a cessar as matrículas para os cursos de formação profissional, garantindo apenas aos alunos já matriculados o direito de concluir seus estudos. Embora o programa da reforma fosse mais complexo e incluísse várias ações e projetos que seriam desenvolvidos pela SEED e pelas escolas, a sua face aparente restringiu-se, no primeiro momento, à forma autoritária de fechamento dos cursos profissionalizantes.

A análise da reforma do ensino médio exige certo detalhamento a respeito do documento síntese do Programa Expansão, Melhoria e Inovação no Ensino Médio do Paraná (PROEM) $)^{3}$, posto que este documento reúne os princípios que orientaram as mudanças no investimento, na organização, na direção de expansão das matrículas e, sobretudo, na concepção que norteia o ensino. Algumas análises já foram construídas em relação ao PROEM (TAVARES, 1999; SILVA, 1999; BARROS, 1998; DEITOS, 2001) e serão tomadas como referência para o desenvolvimento deste artigo.

O PROEM é resultado de um acordo entre o governo do estado do Paraná e o Banco Interamericano de Desenvolvimento, que é responsável por uma parcela significativa do financiamento necessário para a execução do programa, previsto inicialmente para durar cinco anos, a partir de 1998.

É preciso esclarecer que, embora a política de crédito do banco se autodenomine "cooperação técnica", efetiva-se por empréstimos do tipo convencional (...). Integram a dívida externa do país, acarretando os mesmos encargos financeiros, além das condicionalidades políticas e rigidez das regras de prestação de contas. Seguem o modelo de co-financiamento, em que o banco participa com cerca de metade do custo do projeto e o país com a outra metade, denominada "contrapartida". Neste caso, o banco não empresta diretamente, mas ressarce o país pelos gastos realizados, segundo cronograma anual, acordado previamente. Embora a contrapartida nacional deva corresponder à metade do custo do projeto, a experiência dos acordos mostra que essa participação pode chegar a mais de $70 \%$, significando que a maior parte dos recursos vem do próprio governo federal ou dos estados, conforme o caso (FONSECA, 2002, p. 150).

Cabe ressaltar que o programa foi previsto e sua implantação foi inaugurada antes mesmo da aprovação da LDB n. ${ }^{\circ} 9394 / 96$ e do Decreto Federal n. ${ }^{\circ}$ 2208/97 ou o Decreto n..$^{\circ}$ 5154/04 (que substituiu o anterior), que definem as diretrizes para o ensino médio e a formação profissional, em nível nacional. Assim, a reforma desconsidera o contraditório processo de elaboração da LDB e da regulamentação da educação profissional de nível médio, eivado de discordâncias, polêmicas e disputas entre concepções divergentes de educação. Embora o documento do PROEM afirme

\footnotetext{
${ }^{3} \mathrm{O}$ documento oficial que apresenta o PROEM, foi disponibilizado apenas em versões preliminares. A versão utilizada para fins deste estudo foi impressa em junho de 1996.
} 
considerar os estudos e proposições elaboradas para a LDB, não assume claramente sua proximidade com a concepção de educação presente nas primeiras versões do projeto apresentado no Senado por Darcy Ribeiro, do qual tira a idéia de curso "pós-médio" que não existe no texto da lei aprovada.

Antecipando-se ao âmbito federal, a política educacional do ensino médio do Governo do Paraná estabeleceu como diretrizes um melhor atendimento às exigências das novas formas de organização social e do trabalho e aos requerimentos dos avanços tecnológicos, ao mesmo tempo em que se adianta em adaptar-se aos novos marcos legais. A eliminação das habilitações profissionais isoladas dentro do ensino médio, o fortalecimento da educação de formação geral e a criação de Complexos TécnicoEducacionais, de nível Pós-Médio, aproveitando a capacidade já instalada no estado, estão entre as estratégias mais importantes dessa política (PARANÁ, 1996, p. 13).

Estas estratégias consideradas fundamentais foram organizadas em três subprogramas: Melhoria da qualidade do ensino médio; Modernização da Educação Técnica Profissional; e Fortalecimento da Gestão do Sistema Educacional. Para cada um destes subprogramas foram pensados projetos e atividades para que fosse possível atingir os objetivos enunciados, ao final da implantação do programa.

Em relação aos projetos e atividades planejados, cabe ressaltar aqueles que melhor expressam a concepção do programa e que, potencialmente, poderiam ter maiores impactos no trabalho pedagógico no interior da escola. $\mathrm{O}$ primeiro subprograma prevê a melhoria da qualidade do ensino médio, que é traduzido como melhoria da qualidade da educação geral.

O projeto pretendia adotar "um novo modelo de Estabelecimento de Ensino Médio juntamente com as séries de $5^{a}$ a $8^{a}$ do Ensino Fundamental, quando a união dos dois níveis se justifique em função da demanda e do critério de eficiência." (PARANÁ, 1996, p. 17) Este novo modelo foi realmente implantado, tendo em vista que o processo de municipalização, desde o início dos anos 90, ocupou-se de desmembrar o ensino fundamental, deixando as séries iniciais sob a responsabilidade dos municípios. Importa ressaltar que o critério apontado pelo programa desconsiderou plenamente as questões pedagógicas e a necessidade de unitariedade do ensino fundamental, indicando apenas o atendimento à demanda e a eficiência como aspectos a serem analisados para a organização destes estabelecimentos.

O desenvolvimento de um novo desenho curricular também foi apresentado como um aspecto fundamental do programa, sendo que os currículos das escolas de ensino médio deveriam passar a ser norteados por competências cognitivas e sociais, seguindo a tendência à incorporação da pedagogia das competências antes mesmo desta 
concepção ser integrada à política oficial através da Resolução CEB/CNE n. ${ }^{\circ}$ 3, de 26 de junho de 1998, que institui as Diretrizes Curriculares Nacionais para o Ensino Médio. A partir da aprovação das diretrizes, entre os anos de 2000 e 2002, a Secretaria de Estado da Educação passou a exigir que as escolas de ensino médio adaptassem seus projetos pedagógicos incorporando tais idéias. A organização do currículo e os planos das disciplinas de ensino médio deveriam prever as competências e habilidades a serem desenvolvidas junto aos alunos.

No programa, as áreas do conhecimento não são tratadas com isonomia, pois ele prevê a existência de assessoramentos apenas para os professores das áreas de matemática, física, química e biologia, com equipes volantes que atenderiam várias unidades escolares. Percebe-se que não há qualquer referência a assessoramentos para as áreas de linguagens e ciências humanas, o que demonstra a falta de preocupação com estas áreas de conhecimento. Cabe ressaltar que a política de organização de assessoramentos, aparentemente voltados para a metodologia de ensino e utilização de recursos didáticos, portanto restritos a técnicas de ensino, substitui a qualificação e formação continuada dos professores.

Percebe-se também grande ênfase nas questões técnicas e físicas em detrimento das pedagógicas. Ao concordarem em aderir ao PROEM, as escolas estaduais passavam por um processo de reforma física, que na maioria dos casos restringiu-se à pintura e construção de uma nova fachada. Percebe-se grande preocupação com a otimização do quadro de recursos humanos, com a proposição de modificar a relação entre número de alunos por professor, aumentando de 20 para 36 até o final da implantação do programa, o que significou um aumento de $80 \%$. Há ênfase, também, na questão tecnológica, mas a resume à instalação de microcomputadores nas escolas.

Alguns projetos incentivados pelo programa fundamentam-se no princípio de competitividade, que se manifesta também na intenção de adotar um processo de monitoramento e avaliação de rendimentos e resultados da proposta curricular implantada, como insumo para estabelecer mecanismos de aperfeiçoamento. A avaliação centrada em resultados e não no processo de ensino aprendizagem tem suas origens na preocupação com a produtividade e na utilização do modelo empresarial para gerir a educação.

De acordo com o chefe do Departamento do Ensino Médio da SEED em 2003, a gestão anterior preocupou-se em demasia com a realização das avaliações de resultado, em detrimento de discussões sobre a concepção destas avaliações e da análise das 
condições que geraram tais resultados. Assim, as avaliações podem indicar situações que merecem a intervenção da SEED, mas não de forma cabal, posto que os critérios e os mecanismos utilizados são considerados tecnicamente neutros, como se não houvesse um aspecto político na sua definição. As avaliações englobam tanto as ações realizadas pela SEED, como os cursos destinados aos professores, quanto as realizadas pelas escolas.

O segundo subprograma apresentado pelo PROEM é a Modernização da Educação Técnica Profissional, que tinha como sua principal característica a oferta apenas em nível pós-médio. Embora a legislação não indique a existência deste nível de ensino, a reforma do ensino médio no estado do Paraná instituiu a sua existência, que foi incorporada pelos estabelecimentos de ensino e pela linguagem dos profissionais e da população atendida.

O programa previa a criação de 11 Complexos de Educação Técnica Profissional (COMTEC) voltados para a demanda do mercado de trabalho local nos pólos de desenvolvimento econômico do estado, substituindo a oferta dos cursos profissionalizantes nas diferentes escolas públicas estaduais. A idéia de regionalização da oferta pauta-se sobre a intenção de atender as necessidades e vocações do mercado em cada região, o que significa oferecer a formação profissional requerida pelo mercado local.

A explicação para este atrelamento unidirecional da escola ao mercado se mantém sobre dois aspectos principais: o primeiro diz respeito à falta de produtividade quando o sistema escolar forma profissionais em demasia, que não serão absorvidos pelo mercado, pois o investimento nesta formação é compreendido como desnecessário e, portanto se manifesta como desperdício. O segundo aspecto apresentado pelo documento consiste na defesa de que a oferta pulverizada não garante a qualidade dos cursos ofertados, uma vez que ficam à mercê das condições locais, nem sempre favoráveis.

O processo de regionalização da oferta pode provocar a restrição do acesso aos cursos de formação profissional que, antes da reforma, estavam atendendo à maioria dos alunos do ensino médio. Segundo o documento que apresenta o PROEM, em 1995 havia 185.718 alunos matriculados em cursos profissionalizantes nas escolas públicas estaduais. A previsão do programa reduzia o número de vagas para apenas 13.000, considerando a capacidade máxima de todos os complexos que deveriam ser constituídos. 
A redução do número de vagas para estes cursos manifesta um intenso processo de restrição do acesso à formação profissional, mesmo para os egressos do ensino médio, uma vez que o total de vagas que deveriam ser ofertadas não chega a 5\% do total de concluintes do ensino médio regular. Esta redução de matrículas para a formação profissional encontra respaldo nos documentos que definem a política de organismos internacionais, onde se evidencia a idéia de que a educação geral é economicamente mais adequada para o estado, pois remete ao mercado a responsabilidade pelo treinamento do futuro trabalhador.

Um dos princípios básicos na organização do PROEM é a empregabilidade, daí a importância deste tipo de estudo que analisa as relações entre a formação escolar dos alunos e sua inserção no mercado de trabalho. De acordo com o documento da SEED, a intenção central destes estudos é a modernização curricular dos cursos profissionalizantes "tendo em vista sua flexibilidade, adequabilidade ao mercado de trabalho e às necessidades de emprego dos alunos jovens e adultos" (PARANÁ, 1996, p. 52). Contudo, tendo em vista a totalidade da reforma, julga-se que, da forma como tem sido utilizado, o conceito de empregabilidade atende em menor grau as necessidades dos alunos e em maior grau as expectativas das empresas, face às novas exigências do mundo produtivo.

A idéia de empregabilidade é concebida como uma característica ou competência que o sujeito deve adquirir e, em conseqüência, que a escola deve possibilitar. Nesta perspectiva, a condição de trabalhador empregável pode ser conquistada por meio da adequação dos cursos de formação geral e profissional às exigências do mercado de trabalho.

A denunciada "inadequação" é um pressuposto que justifica a continuidade da política educacional atrelada aos interesses econômicos e políticos locais e nacionais, articuladas aos interesses internacionais. Reforça-se o caráter da educação como "promotora" do desenvolvimento e como via de ascensão social, por meio da promoção da empregabilidade (DEITOS, 2001, p. 262).

A proposta de instalar um "currículo de especialidades adequadas à demanda do mercado de trabalho nos pólos de desenvolvimento do Estado" (PARANÁ, 1996, p. 48) demonstra a falta de perspectiva de futuro do programa, pois as demandas imediatas são expressão de uma situação conjuntural que não pode ser tomada como pressuposto para a organização de um sistema ou rede de ensino, sob pena de falência do mesmo.

Muitas análises têm sido construídas a respeito da idéia de empregabilidade, que remete aos sujeitos a responsabilidade por manterem-se "empregáveis" num mundo 
onde as relações econômicas sobrepõem-se às relações humanas. A empregabilidade pode ser compreendida como a versão, para o trabalhador, do princípio de flexibilidade de produção, uma vez que a instauração de relações de emprego mais flexíveis deve ser acompanhada de uma ideologia que explique e justifique a exclusão.

O terceiro e último subprograma que compõe o PROEM refere-se ao Fortalecimento da Gestão do Sistema Educacional. Neste item as questões que podem ser consideradas mais relevantes são as propostas de gestão administrativa e financeira e a concepção de autonomia das escolas.

A análise das ações que envolvem a gestão administrativa e financeira das escolas previstas no documento demonstra que o principal componente deste subprograma é a participação e o apoio do setor produtivo privado e da sociedade civil. O programa indica a necessidade de comunicação entre escolas, empresas e sociedade civil a fim de construir mecanismos de recuperação de custos, garantir a transparência na prestação de contas e na gestão financeira, além de definir critérios de mérito na administração de pessoal.

A concepção de autonomia utilizada no documento é bastante reducionista, uma vez que se resume à idéia de descentralizar, desconcentrar e compartilhar decisões entre escolas e secretaria, tendo o suporte político e social da comunidade. Evidencia-se que o apoio e suporte da comunidade são compreendidos como a constituição de "parcerias que permitam viabilizar mecanismos de sustentação econômica das ações implementadas" (PARANÁ, 1996, p. 55). A comunidade escolar aparece reiteradas vezes nas metas dos três subprogramas que compõem o PROEM, sempre com o objetivo de validar as propostas do governo. A participação da comunidade na condução do processo educativo e na tomada de decisões é um princípio fundamental para a democratização da educação, mas isso não pode significar apoio financeiro e material para o funcionamento da escola.

Assim, percebe-se que não há um compromisso com a democratização das relações de decisão política. Ao contrário, como demonstram vários estudos realizados neste campo e já citados anteriormente, a utilização de mecanismos de descentralização, sobretudo financeira, muitas vezes, como neste caso, gera um descompromisso do poder público em relação à manutenção da educação. Neste subprograma estava previsto também um projeto de mobilização social e marketing para divulgação do PROEM, o que foi feito com certo sucesso, uma vez que sua concepção, estrutura e linguagem foram incorporadas pela população atendida no ensino médio. 
Os grandes objetivos declarados da reforma gravitam em torno do atendimento às necessidades e exigências do mercado de trabalho, portanto o trinômio eqüidade, eficiência e eficácia é apresentado como o paradigma essencial da reforma. De acordo com o documento que apresenta o PROEM,

a eqüidade é requisito fundamental para corrigir as disparidades no acesso, tendo em vista que a origem social da clientela não pode ser o elemento determinante para o acesso ou não à escola e para determinar diferenciações quanto ao domínio dos conhecimentos e competências indispensáveis à sociedade contemporânea. (...) A eficácia pressupõe que se elevem os níveis de desempenho das aprendizagens de conteúdos gerais, assegurada a adequação e pertinência da oferta às exigências econômicas e sociais. (...) A eficiência é uma condição da eficácia, e impõe a otimização dos recursos humanos financeiros e de infra-estrutura (PARANÁ, 1996, p. $3-4)$.

Estes três princípios são considerados fundamentais para a melhoria da qualidade do ensino médio, que por sua vez é tomado como condição essencial para a retomada de desenvolvimento estadual. É possível perceber que o horizonte estabelecido pela reforma é atender as necessidades impostas pelo processo de reestruturação produtiva. A educação é concebida como motor do desenvolvimento econômico e a reforma busca adaptá-la ao modelo de produção do estado. Esta proposição é, em certa medida, idealista na medida em que considera que a escola, por si mesma, alavanca o desenvolvimento econômico. É evidente que a escolarização da população é importante para o desenvolvimento, mas não é a única determinante. Assim, a grande questão que se apresenta é a ausência de preocupação com a formação humana dos jovens, que permanece subsumida ao aspecto econômico.

A análise dos impactos provocados pela realização das ações propostas pela reforma pode contribuir para uma reflexão de totalidade a respeito das consequiências destes princípios para a educação. $\mathrm{O}$ aspecto que mais chama a atenção quando se trata da otimização de recursos, buscando eficácia e eficiência no processo educativo, é a drástica redução de investimento público destinado ao ensino médio.

O relatório da pesquisa sobre o Impacto do Fundo de Manutenção e Desenvolvimento do Ensino Fundamental e de Valorização do Magistério - FUNDEF no Estado do Paraná ${ }^{4}$ mostra que, apesar de se verificar um grande crescimento da

\footnotetext{
${ }^{4}$ Esta pesquisa, sobre o Impacto do Fundo de Manutenção e Desenvolvimento do Ensino Fundamental e de Valorização do Magistério - FUNDEF - no Estado do Paraná, foi realizada por um grupo de professores e alunos da UFPR e representantes dos sindicatos APP - Sindicato, SISMMAC e SISMMAR. O grupo estadual estava vinculado ao grupo nacional, organizado por professores da USP, e recebeu financiamento da Fundação Ford para desenvolver a pesquisa em diversos estados brasileiros. O grupo analisou as receitas e gastos com educação do estado e cinco municípios, verificando a utilização do total
} 
arrecadação de receitas no período entre 1996 e 2000, o que deveria gerar maior disponibilidade de recursos para o ensino, o investimento em educação foi sendo progressivamente diminuído. Em 2000, o estado do Paraná gastou 13,5\% menos com a função educação e cultura do que em 1996.

A redução dos gastos com o ensino médio neste período foi o que mais contribuiu para este impacto negativo sobre os investimentos em educação e cultura. Após um incremento de pouco mais de 18\% entre 1996 e 1997, verifica-se uma linha acentuada de queda nos investimentos neste nível de ensino, até 2000. No último ano desta amostra o governo do estado gastou quase $60 \%$ a menos com o ensino médio do que gastava em 1996.

A Tabela 1, abaixo, demonstra o cálculo do valor de gastos anuais por aluno nas escolas da rede estadual de ensino. A linha das despesas mostra o total de investimentos no ensino médio de 1996 a 2000, período que congrega os anos anteriores à reforma e o início de sua implantação. Os dados de despesa foram cruzados com as informações sobre o número total de matrículas no ensino médio regular, noturno e diurno. $\mathrm{O}$ resultado é bastante inesperado, pois enquanto os gastos totais foram reduzidos em $59,2 \%$, o gasto-aluno foi reduzido em $68,3 \%$. Considerando apenas o intervalo entre 1997 (ano da amostra em houve maior investimento) e 2000, a redução dos gastos por aluno chega a $71,3 \%$.

Tabela 1. Gasto-aluno no Ensino Médio na Rede Estadual do Paraná - 96/00

\begin{tabular}{cccccc}
\hline & $\mathbf{1 9 9 6}$ & $\mathbf{1 9 9 7}$ & $\mathbf{1 9 9 8}$ & $\mathbf{1 9 9 9}$ & $\mathbf{2 0 0 0}$ \\
\hline $\begin{array}{c}\text { Despes } \\
\text { as }\end{array}$ & $455.215 .865,8$ & $773.537 .111,2$ & $178.627 .955,5$ & $182.988 .961,7$ & $190.103 .541,1$ \\
\hline Alunos & 336.641 & 361.270 & 396.745 & 456.290 & 433.151 \\
\hline $\begin{array}{c}\text { Gasto- } \\
\text { aluno }\end{array}$ & $1.352,23$ & $2.141,16$ & 450,23 & 401,04 & 438,89 \\
\hline
\end{tabular}

Fonte: Relatório de pesquisa: Implantação e Impactos do FUNDEF no Paraná: o caso da rede estadual de ensino In GOUVEIA et al., 2001.

Nota: Valores das Despesas e Gasto-Aluno em reais, atualizados para valores de janeiro de 2003, pelo IGP-Médio do DIEESE.

Esta redução dos investimentos no ensino médio pode ser explicada, em parte, pela extinção dos cursos profissionalizantes, posto que são mais onerosos do que os cursos de formação geral. Contudo, a redução é tão significativa que apenas este dado não é suficiente para explicá-la em sua totalidade. Cabe ressaltar que é possível que 
alguns gastos com o ensino médio estejam computados na prestação de contas do ensino fundamental, tendo em vista que muitas escolas e professores atendem os dois níveis.

Em 1996 o gasto-aluno no ensino médio era 39,6\% maior do que o gasto-aluno no ensino fundamental. Ao longo do período analisado esta situação se inverte e, em 2000, o ensino fundamental passa a ter um gasto-aluno 60,5\% maior do que o ensino médio. Os investimentos no ensino fundamental aumentaram em apenas 24,7\%, mas a redução dos gastos com o ensino médio levou ao aumento significativo deste índice.

De acordo com as informações cedidas pelo Chefe do Departamento do Ensino Médio da SEED em 2003, a gestão do governo anterior não utilizou os recursos previstos pelo PROEM em 2001 e 2002, sendo que no final da gestão houve uma "sobra" de recursos da ordem de R 96 milhões que deveriam ter sido investidos. Mesmo sem ter sido utilizado todo o recurso vinculado ao empréstimo, o governo estadual começou a pagar, naquele ano, os juros pelo empréstimo, que chegavam a $7,5 \%$ ao ano.

Parece incoerente que uma reforma que defende a melhoria da qualidade no ensino se efetive com tamanha redução nos investimentos em educação. Em tese, um ensino de qualidade demanda investimentos financeiros e pedagógicos, o que não se verificou nas ações da SEED entre 1998 e 2002. O ensino médio teve, pela primeira vez no estado do Paraná, uma fonte de recursos própria para sua manutenção e desenvolvimento, o que poderia ter se traduzido em grande avanço na medida em que de fato garantisse um incremento no financiamento público para esta etapa da educação básica.

Contudo, verificou-se uma redução significativa e abrupta do gasto anual por aluno depois do contrato firmado com o BID. Este dado contrapõe-se frontalmente aos discursos oficiais que procuram convencer a população de que os recursos existem, estão disponíveis e são suficientes, mas a má gestão dos mesmos não possibilita a superação das mazelas enfrentadas pela escola pública. O que se verifica de fato, por meio das informações disponibilizadas pelo próprio poder público, é que os recursos estão cada vez mais exíguos, sendo muitas vezes insuficientes para a manutenção e desenvolvimento de um ensino de qualidade para todos.

É possível considerar que a redução nos investimentos por aluno com o ensino médio só não foi maior porque houve uma leve queda no total de alunos matriculados em 2000, tendência que se apresenta constante nos anos subseqüentes. Entre 1996 e 1999 a rede estadual de ensino recebeu 119.649 alunos novos, ratificando a previsão de 
que o aumento nos índices de conclusão do ensino fundamental demandaria incremento na demanda de vagas para o ensino médio.

O documento que apresenta o PROEM traz uma projeção de que a rede estadual deveria chegar a atender 450 mil alunos no ensino médio, dentro de um prazo de 5 anos. Em 1999 o número de matrículas ultrapassou esta previsão, chegando a 456.290 alunos, mas nos anos seguintes a quantidade de alunos freqüentando o ensino médio foi diminuindo e, em 2002, este número baixou para 407.751 alunos, como mostram os dados organizados na Tabela 2.

Tabela 2 - Matrículas no Ensino Médio por Dependência Administrativa, no Estado do Paraná, de 1995 a 2002

\begin{tabular}{cccccccccccc}
\hline \multicolumn{10}{c}{} & \multicolumn{10}{c}{ Dependência Administrativa } \\
\hline Ano & Federal & $\%$ & Estadual & $\%$ & Municipal & $\%$ & $\begin{array}{c}\text { Rede } \\
\text { Pública }\end{array}$ & $\%$ & Particular & $\%$ & Total \\
& & & & & & & & & & & \\
\hline 1995 & 11.851 & 3,4 & 302.017 & 85,9 & 195 & 0,06 & 314.063 & 89,3 & 37.675 & 10,7 & 351.738 \\
\hline 1996 & 12.551 & 3,1 & 336.641 & 84,0 & 276 & 0,07 & 349.468 & 87,2 & 51.100 & 12,8 & 400.568 \\
\hline 1997 & 12.463 & 2,9 & 361.270 & 84,7 & 69 & 0,02 & 373.802 & 87,7 & 52.504 & 12,3 & 426.306 \\
\hline 1998 & 11.091 & 2,4 & 396.745 & 85,7 & 0 & - & 407.836 & 88,1 & 55.324 & 11,9 & 463.160 \\
\hline 1999 & 8.673 & 1,7 & 456.290 & 88,0 & 113 & 0,02 & 465.076 & 89,7 & 53.211 & 10,3 & 518.287 \\
\hline 2000 & 7.775 & 1,6 & 433.151 & 88,2 & 102 & 0,02 & 441.028 & 89,8 & 50.067 & 10,2 & 491.095 \\
\hline 2001 & 4.831 & 1,0 & 417.382 & 88,4 & 0 & - & 422.213 & 89,4 & 50.150 & 10,6 & 472.363 \\
\hline 2002 & 4.621 & 1,0 & 407.751 & 88,1 & 0 & - & 412.876 & 89,1 & 50.362 & 10,9 & 462.734 \\
\hline & & Fonte: MEC/INEP/SEEC & SEED/FUNDEPAR & & & & &
\end{tabular}

Fonte: MEC/INEP/SEEC - SEED/FUNDEPAR

Nota: Os dados não incluem os alunos matriculados na EJA

Este "desaparecimento" dos alunos do ensino médio, quando a previsão seria a continuidade de expansão das matrículas, tendo em vista que o ensino fundamental está praticamente universalizado e, a cada ano, há um aumento do número de concluintes da $8^{\text {a }}$ série, pode ser parcialmente explicado pelo aumento do número de matrículas nas classes de educação de pessoas jovens e adultas (EJA) e do número de exames realizados neste período. Somente na rede estadual de ensino, de 1997 para 2000, houve um incremento de 109.435 alunos freqüentando a EJA ou realizando os exames correspondentes ao ensino médio.

Considera-se que a diminuição de idade para a realização dos exames, de acordo com a LDB n. ${ }^{\circ}$ 9394/96, além da política executada pelo governo estadual de incentivo para sua realização pelos jovens, tenha contribuído para este aumento significativo. Contudo, embora seja bastante elevada a porcentagem de alunos que aderiu à EJA e aos exames, este dado não explica totalmente o decréscimo de matrículas no ensino médio regular, pois muitas destas pessoas não estavam freqüentando a escola regular. 
Outra hipótese possível para a explicação do aumento de matrículas no ensino médio no final da década de 1990, pode ser como conseqüência dos programas de correção de fluxo ou aceleração de estudos para os alunos que freqüentavam o ensino fundamental com certa defasagem idade-série. Cabe, ainda, a realização de outros estudos que busquem explicar este fenômeno.

A análise da política educacional exige uma reflexão sistemática a respeito do seu financiamento, principalmente em relação às fontes e aos gastos dos recursos públicos, e de sua efetividade, principalmente em relação à população atendida e à qualidade do serviço público. Decorre desta necessidade a importância da demonstração da diminuição significativa dos investimentos da administração pública estadual no ensino médio antes e depois da implementação do PROEM. Há que se refletir sobre a veracidade do ideal de melhoria concreta da qualidade desta etapa da educação básica, indicado pelo programa em questão, tendo em vista que apenas dois anos depois do início da reforma, os balanços financeiros do estado do Paraná apontam uma redução expressiva do custo aluno anual.

Verifica-se que, embora a reforma tenha captado US\$ 100 milhões junto ao BID e conte com mais US\$ 122 milhões da contrapartida do governo estadual, isso não se refletiu em benefícios concretos para os alunos e as escolas. Considera-se que uma reforma que tenha como objetivo real a melhoria da qualidade do ensino oferecido à população exige ampliação de recursos e investimentos de ordem financeira e pedagógica. Portanto, há certa incoerência entre os objetivos propalados pelo PROEM e realização da reforma encaminhada pela SEED no período analisado.

Os princípios coincidentes entre a reforma do ensino médio no estado do Paraná e as definições presentes nos documentos do Banco Mundial (1991), no Planejamento Estratégico do MEC (1995-1998) e nas Diretrizes Curriculares Nacionais para o Ensino Médio (1998) não são resultado de um simples processo de cumprimento de exigências, mas representam sobretudo a aceitação e concordância da administração pública local, em âmbito estadual, com os princípios defendidos por aqueles organismos.

Vários dos mecanismos presentes na reforma não são necessariamente exigências das instituições de financiamento internacional, como a cessação das matrículas dos cursos de educação profissional de nível médio no estado do Paraná, que foi proposta pelo governo estadual antes mesmo do início de implantação oficial do PROEM. 


\section{Referências Bibliográficas}

BANCO MUNDIAL. Educación técnica y formación profesional. Documento de política del Banco Mundial. Washington, 1991.

BUENO, M. S. Orientações nocionais para a reforma do ensino médio: dogma e liturgia. In: Cadernos de Pesquisa, $n^{\circ}$ 109, março de 2000, Fundação Carlos Chagas: AA.

CURY, C. R J. Lei de Diretrizes e Bases e perspectivas da educação nacional. In: Revista Brasileira de Educação. Nº. 8, mai/ago 1998, p. 72-84.

DEITOS, R. A. Da afirmação da inadequação da política educacional paranaense para o ensino médio e profissional à adequação às exigências políticas e econômicas hegemônicas (1995-1999). In: HIDALGO, Ângela Maria (org.). Educação e Estado: as mudanças nos sistemas de ensino do Brasil e Paraná na década de 90. Londrina: Ed. UEL, 2001.

FERRETTI, C. Mudanças em sistemas estaduais de ensino em face das reformas no Ensino Médio e no Ensino Técnico. In: Educação \& Sociedade, n. ${ }^{\circ} 70$ - 2000. Campinas: Cedes.

FONSECA, M. Perspectivas para a gestão e financiamento do ensino médio. In: ZIBAS; AGUIAR; BUENO. O ensino médio e a reforma da educação básica. Brasília: Plano, 2002.

GOUVEIA, A. et. al. Impactos da implantação do FUNDEF no estado do Paraná. Relatório de Pesquisa. Curitiba: Setor de Educação/UFPR, 2001.

KUENZER, A. Ensino Médio: construindo uma proposta para os que vivem do trabalho. São Paulo: Cortez, 2000.

NUNES, C. Ensino Médio. Diretrizes Curriculares Nacionais. Rio de Janeiro: DP\&A, 2002.

PARANÁ. Programa Expansão, Melhoria e Inovação do Ensino Médio do Paraná PROEM. Documento Síntese. Curitiba, julho, 1996.

. Relatório de Atividades de 1998. Curitiba, fevereiro, 1999.

. Relatório de Atividades de 2001. Curitiba, fevereiro, 2002.

. Termo de Referência n. ${ }^{\circ}$ 031/2002.

Projeto Qualidade no Ensino Público do Paraná. Contrato de empréstimo n. ${ }^{\circ}$ 3766 - BR. Termo de Referência n. ${ }^{\circ}$ xxx/00.

Contrato de empréstimo n. 3766 - BR. Termo de Referência n. ${ }^{o}$ 205/2001. Centro de Protagonismo Juvenil.

ROSAR, M. F. F. \& KRAWCZYC, N. Diferenças da homogeneidade: elementos para o estudo da política educacional na América Latina. In: Educação \&Sociedade. Campinas: Cedes. n. ${ }^{\circ} 75,2001$, p. 33-47

SANTOS, J. As políticas governamentais para o ensino fundamental no estado do Paraná diante dos preceitos da Constituição. São Paulo, 1998, Tese (Doutorado em Educação) FEUSP. 
TAVARES, T. PROEM: Formação para o mercado de trabalho e o desmonte da perpectiva do Ensino Médio enquanto Educação Básica e o ensino técnico profissional. In: Caderno Pedagógico n. ${ }^{\circ}$ 2, março de 1999, Curitiba: APP- Sindicato.

ZIBAS, D. (Re) significando a reforma do ensino médio: o discurso oficial e os filtros institucionais. In: ZIBAS; AGUIAR; BUENO. O encino médio e a reforma da educação básica. Brasília: Plano, 2002. 